\title{
Functional Assessment of Chronic Illness Therapy-Treatment Satisfaction-General
}

National Cancer Institute

\section{Source}

National Cancer Institute. Functional Assessment of Chronic Illness Therapy-Treatment

Satisfaction-General. NCl Thesaurus. Code C121902.

A patient-reported outcome measure designed specifically to evaluate general

satisfaction with treatment. 